\title{
Evaluation of Psychopathological Conditions, Corona Anxiety, Death Anxiety and Suicide Risk in Hemodialysis Patients During the COVID-19 Pandemic
}

Süleyman Korkut ( $\nabla$ dr.korkut@hotmail.com )

Antalya Eğitim ve Araştırma Hastanesi https://orcid.org/0000-0003-2196-176X

\section{Research Article}

Keywords: COVID-19, Hemodialysis, Psychopathology, Corona anxiety, Death anxiety, Suicide risk

Posted Date: January 4th, 2022

DOl: https://doi.org/10.21203/rs.3.rs-1211968/v1

License: (c) (i) This work is licensed under a Creative Commons Attribution 4.0 International License. Read Full License 


\section{Abstract \\ Background}

Hemodialysis (HD) patients have serious psychopathological symptoms due to COVID-19 pandemic. Therefore, this study aimed to identify the psychopathological conditions among HD patients during the current pandemic and also to provide a theoretical basis for the implementation of effective preventions and psychological interventions.

\section{Methods}

This cross-sectional study was conducted with $114 \mathrm{HD}$ patients who were undergoing treatment in the Dialysis Centers of two state hospitals between July and October 2021. Brief symptom inventory, Death anxiety scale, Suicide probability scale and Corona anxiety scale were applied to the participants for the assessment.

\section{Results}

In the study, it was determined that HD patients had high levels of psychopathological symptoms. The mean total score was found to be $26.47 \pm 20.2$ in TDAS, $0.71 \pm 0.51$ in GSI, $3.31 \pm 2.86$ in CAS and $65.86 \pm 9.72$ in SPS. Of the participants $18.4 \%$ had high death anxiety levels and $30.7 \%$ had corona anxiety. Suicide risk was higher in HD patients. In correlation analysis; psychological distress positively correlated with suicide probability, corona anxiety and death anxiety. On the other hand, there was a positive correlation between corona anxiety and death anxiety.

\section{Conclusions}

As a result, it was concluded that HD patients experienced various mental health problems during the COVID19 pandemic. Psychosocial support and interventions need to be planned by the healthcare system and healthcare providers to help HD patients in managing their disease and related mental health conditions.

\section{Introduction}

The new Coronavirus disease 2019 (COVID-19), which firstly emerged in China and spread quickly around the world. World Health Organization declared COVID-19 as a pandemic on March 2020 [1]. The virus that causes COVID-19 has been defined as severe acute respiratory syndrome coronavirus 2 (SARS-CoV-2) by the Coronaviridae Study Group [2]. Currently, there is no curative treatment for COVID disease. Also, the primary scope of the studies is to prevent the spread of SARS-CoV-2. Due to the high transmissibility and high mortality of SARS-CoV-2, serious health problems have emerged or existing health problems have increased.

Renal replacement therapy (RRT) is applied in patients diagnosed with end-stage renal disease (ESRD). The most commonly used RRT method in our country is haemodialysis (HD) (77.3\%), followed by transplantation 
(17.4\%) and peritoneal dialysis (5.3\%). The prevalence was calculated as 935 per million population and the incidence as 147 per million population [3]. As in many other chronic diseases, serious physiological and psychological problems are seen in HD patients. It has been demonstrated that the incidence of psychiatric psychopathology is higher in HD patients than in the general population [4].

COVID-19 threatens the lives of people, especially those with chronic diseases (diabetes mellitus, hypertension, chronic renal failure, etc.) [5,6]. Additionally, mortality rates in dialysis patients infected with SARS-CoV-2 during the COVID-19 outbreak were found to be higher than in the normal population $[7,8]$. In addition to having a chronic disease in HD patients, the risk of getting infected with SARS-CoV-2 increases stress and anxiety. Serious psychopathological problems may occur due to high levels of anxiety such as death anxiety, corona anxiety, generalized anxiety, phobic anxiety. In a study which conducted with HD patients during the COVID-19, it was found that anxiety and depression symptoms increased [9].

It has been found that among HD patients, suicide is the most serious consequence of mental disorder, and these patients are more likely to suicide than the general population [10]. In accordance with this, a high incidence of suicide threats and attempts has been demonstrated among HD patients [11].

In the literature, there are limited studies focusing on the psychopathological conditions of HD patients during the COVID-19 pandemic. It is necessary to investigate the effects of the COVID-19 pandemic on the mental problems of HD patients from a comprehensive perspective. Therefore, this study aims to identify the psychopathological conditions among HD patients during the current pandemic and also to provide a theoretical basis for the implementation of effective preventions and psychological intervention.

\section{Methods}

This cross-sectional study was conducted with $114 \mathrm{HD}$ patients who have been under treatment in the Dialysis Centers of two state hospitals in Antalya, in Turkey, between July-October 2021.

Participants were randomly selected. Sociodemographic data form was filled for each participant. In accordance with the purpose of the study; Brief symptom inventory, Death anxiety scale, Suicide probability scale and Corona anxiety scale were administered to the participants. Criteria for inclusion were as following; willing to participate in the study, above 18 years old, undergoing HD replacement therapy for at least 1 year, capable to read or understand the contents of the scales and able to communicate. Criteria for exclusion were as following; have psychiatric treatment in the last 3 months, have another chronical illness, have serious mental problem that will impair the cognition (e.g. dementia, mental retardation, epilepsy, alcohol/substance abuse or addiction, psychosis). Informed consent form was obtained from all participants for the study. This study was conducted according to the Declaration of Helsinki. The local ethics committee approved. Approval was obtained from the Ethics Committee of the Antalya Training and Research Hospital for the study (Approval number: 2021-167).

\section{Psychometric assessment}

\section{Brief symptom inventory (BSI)}


The BSI performed to evaluate psychopathological and psychological symptoms [12]. The BSI is a 53-item self-report, 5-point Likert scale, ranging from 0 ("not at all") to 4 ("extremely"). The BSI contains nine symptom subscales, namely; somatization, obsession-compulsion, interpersonal sensitivity, depression, anxiety, hostility, phobic anxiety, paranoid ideation and psychoticism. Subscales are determined by dividing the total score of the items by the number of items. The global severity index (GSI) is a summary index of psychological distress, was used as the primary BSI outcome measure. GSI is determined by the total score of all items divided by total item number. High scores are characteristic of participants with greater psychological distress $[13,14]$. The validity and reliability study of the Turkish version was performed [15].

\section{Turkish Death Anxiety Scale}

The concurrent validity of the TDAS was studied by its relationships with the Revised-DAS (RDAS) which developed by Thorson\&Powell [16]. The scale includes 20 items scored on a 5-point Likert ranging from 0 (never) to 4 (always). The total scale scores may range from 0 to 80 and the higher scores indicate the higher levels of death anxiety. Cut-off scores for the total TDAS to be 0-7 (very low level anxiety); 8-25 (low level anxiety); 26-44 (medium level anxiety); 45-63 (high level anxiety); and 64-80 (very high level anxiety). ) The validity and reliability study of the Turkish version was performed [17].

\section{Suicide Probability Scale (SPS)}

The scale was developed to evaluate the suicide risk [18]. It is a four-point Likert-type ranging from 1 (never) to 4 (always) and self-assessment scale with 36 items. The aim of the scale is to assess suicide risk. The higher overall score indicates the higher risk of suicide. Validity and reliability of the Turkish version of the scale was conducted by Atli et al. [19].

\section{Coronavirus Anxiety Scale (CAS)}

CAS developed to identify possible causes of dysfunctional anxiety associated with the COVID-19 pandemic [20]. The scale is 5-point Likert-type scale ranging from 0 (not at all) to 4 (nearly every day) and includes 5 items. The optimized cut-off score of CAS was found as point of $\geq 5$ [21]. The Turkish validity and reliability study of the scale was conducted by Biçer et al. [22].

\section{Statistical analysis}

Number and percentage distribution, mean and standard deviation values were used for the analysis of the patients'socio-demographic characteristics. Independent sample t-test was used to determine the differences between groups. Chi-square analysis was used to test the homogeneity of the groups and the relationships of categorical variables. ANOVA test was used to compare the between group differences. Tukey HSD test was used to determine the source of differentiation. Pearson's correlation analysis was used to evaluate the relationship between variables. The value of statistical significance was accepted as $p<0.05$ in all tests. Statistical analysis was performed using the 21.0 version of SPSS Windows program.

\section{Results}


The study sample was composed of 114 patients who were undergoing HD therapy. The mean age of the participants was $60.61 \pm 15.10$ (between age of $22-90$ ). Of them, $14 \%$ were below the age of $50,66.7 \%$ were between the age of $50-75$ and $72.3 \%$ were above the age of 75 . Of the participants $52.6 \%$ were men and $47.4 \%$ were women. Of the participants $71.9 \%$ were married, $35.1 \%$ graduated from a university, $81.5 \%$ were living with their family, $28.9 \%$ had history of a pyschiatric disease, $28.1 \%$ were needing of self-care or social support. The sociodemographic characteristics of the participants are shown in Table 1. The mean HD therapy period of the patients was found to be 13.6 years ( $\min : 1.3$, max:28). On the other hand, $2.6 \%(n=3)$ of the participants declared that they were confirmed with COVID-19.

The mean total scores of the BSI subscales were; somatization $0.96 \pm 0.94$, depression $0.91 \pm 0.89$, obsession-compulsion $0.97 \pm 0.64$, interpersonal sensitivity $0.83 \pm 0.56$, anxiety $0.89 \pm 0.79$, hostility $0.61 \pm$ 0.62 , phobic anxiety $0.70 \pm 0.51$, paranoid ideation $0.71 \pm 0.57$, psychoticism $0.62 \pm 0.42$. The mean total score of the GSI was found to be $0.71 \pm 0.51$ (min: 0.13 , max: 2.43 ). GSI was statistically higher among the HD patients who were female, were above the age of 75 , were married, were not university graduated, were needing of self-care or social support and had a history of psychiatric disease.

The mean total score of the TDAS was found to be $26.47 \pm 20.2$ (min:1, max:71). According to the severity level of death anxiety, the results were as following; $23.7 \%(n=27)$ very low , $24.6 \%(n=28)$ low, 33.3\% $(n=38)$ medium, $10.5 \%(n=12)$ high, $7.9 \%(n=9)$ very high. As seen in Table 2, death anxiety was statistically higher among the HD patients who were female, were above the age of 75 , were married, were living with their family and were needing of self-care or social support $(p<0.05)$. The mean total score of the SPS was found to be $65.86 \pm 9.72$ (min:46, max:95). The probability of suicide was statistically higher among the HD patients who were above the age of 75 , were needing of self-care or social support, had a history of psychiatric disease and had history of suicidal ideation ( $p<0.05$ ). (Table 2). The mean total score of CAS in HD patients was $3.31 \pm$ 2.86 (min:0, max:12). Of the participants $30.7 \%$ had corona anxiety (CAS score of $\geq 5$ ). Corona anxiety was statistically higher among the participants who were female $(p<0.05)($ Table 2$)$.

Correlation analysis: The relationship between variables is seen in Table 3. Psychological distress (GSI) positively correlated with suicide probability $(r=0.442 ; p<0.05)$ and corona anxiety $(r=0.414 ; p<0.05)$ and death anxiety $(r=0.667 ; p<0.05),(r=3,66)$. There was also statistically positive correlation between death anxiety and corona anxiety $(r=0.651 ; p<0.05)$. On the other hand, suicide probability positively correlated with corona anxiety $(r=0.042)$ and death anxiety $(r=0.113)$, which was not statistically significant $(p>0.05)$.

\section{Conclusions}

COVID-19 continues to be a serious threat to mental and physical health of individuals. The morbidity and mortality rates due to COVID-19 are increasing gradually. The current number of COVID-19 cases worldwide is about 253 million and the number of deaths is about 5.1 million [23]. Due to the inability to control the pandemic, these numbers are increasing even more. In addition, number of cases indicate the fatality and severity of the pandemic as a global health problem. Moreover, COVID-19 causes various mental health problems or increases existing symptoms such as stress, anxiety, depression, insomnia, phobia, death anxiety, obsession and fear $[24,25,26]$. On the other hand, as a result of many studies, HD patients have common psychopathological symptoms due to the negative effects of their chronical illness $[27,28,29,30]$. 
In addition, in a study which conducted during the COVID-19 pandemic found that, HD patients are highly susceptible to COVID-19 [7]. Also HD patients should be considered as a group at higher risk of mental health problems during the COVID-19. Regarding to current literature, this is one of the limited studies evaluating mental health conditions comprehensively in HD patients during the COVID-19 pandemic. In the limited studies conducted during COVID-19 found an increased incidence of anxiety and depression symptoms and increased psychosocial distress in HD patients [9, 31].

In this study, it was determined that HD patients were seriously negatively affected by the emotional impact of pandemic. Psychopathological symptoms such as somatization, obsession, interpersonal sensitivity, depression, anxiety, hostility, phobic anxiety, paranoid thought, and psychoticism were found to be high. Additionally, psychological distress (GSI is a summary index of psychological distress) was found to be high. Due to the lack of study during COVID-19 which using similar assessment tools in HD patients, comparison could not possible. Therefore, the results of this study compared with the norms of adults nonpatients and compared with the results of a study which included HD patients, before COVID-19 [14, 32]. A series of mental health problems have been triggered by multifactorial effect of various psychosocial conditions during the pandemic. That factors may caused an increase in psychopathological symptoms in HD patients such as limitation of physical activity due to quarantine, susceptibility to emotional problems, uncertainty about pandemic, fear of get infected with virus, hopelessness, difficulties accessing psychosocial support.

Additionally, it was determined that HD patients are at higher risk who who were female, were above age of 75, were married, had not graduated from university, were needing of self-care or social support and had a history of psychiatric disease.

HD patients, who are totally dependent on a machine for survival, have decreased quality of life, have reduced life expectancy and this may lead to death anxiety [33,34]. According to a study, the accessibility of deathrelated thoughts increases during virus pandemics [35] Another study which conducted during COVID-19, it was demonstrated that death anxiety was increased among the patients of HD [36]. In the present study, it was found that the death anxiety of the participants was at medium levels. Additionally, it was determined that $33.3 \%(n=38)$ of the patients had medium level death anxiety, $10.5 \%(n=12)$ had high level death anxiety and $7.9 \%(n=9)$ had very high level death anxiety. Furthermore, HD patients are at higher risk who were female, were above the age of 75 , were married, were living with their family and were needing of self-care or social support. In the context of COVID-19, the high risk of death from the virus in HD patients has been considered as prominent factor that increases death anxiety. Other reasons may be that HD patients had problems such as accessing healthcare facilities during quarantine, having mobility constrains such as routine check-up for dialysis sessions and travel.

HD patients generally have to cope with various psychosocial difficulties in course of their treatment, such as dependency to dialysis and medication regimens, dietary and liquid limitations, limitations in physical activities, time limitations, sexual dysfunctions and anxiety of death. Such as these psychological and physiological problems can lead to suicidal ideation [37]. Corroborative evidence has indicated that the suicide rate among HD patients is higher than general population [11,38]. In a study conducted in the general population during COVID-19, it was found that suicide rates increased [39]. To the best of our knowledge, this is the first study to focus suicide risk on patients undergoing HD during COVID-19. In the present study, it was 
found that the suicide probability of the participants was at moderate levels [19]. Notably, HD patients are at higher risk who were above the age of 75 , were needing of self-care or social support, had a history of psychiatric disease and had history of suicidal ideation. Of the HD patients $11.5 \%$ declared had suicidal ideation in a time of their lives and none of the participants have suicidal ideation during the interview. Additionally, none of them had attempted suicide. Psychosocial problems such as depression, psychological distress, stressful events, uncertainty about the pandemic, death anxiety, decrease in life expectancy, feeling helpless may be the reasons for this result.

Coronavirus anxiety defines to the dysfunctional anxiety associated with the COVID-19 pandemic [20]. In a study conducted in normal population, the rate of coronavirus anxiety (CAS score of $\geq 5$ ) was found to be $54.8 \%$ and in a study conducted with a group of healthcare workers consisting of nurses, it was found to be $37.8 \%[40,41]$ However, no study was found with HD patients in the literature. In present study, the rate of coronavirus anxiety was found to be $30.7 \%$, which lower rate according to other studies mentioned. This may be because the majority of participants had not diagnosed with COVID-19 (only 3 HD patients confirmed with COVID-19).

The study results confirmed that psychological distress positively correlated with suicide probability, corona anxiety and death anxiety. This result clearly indicates that death anxiety, corona anxiety and suicide probability are directly affected by psychological distress. On the other hand, there was a positive correlation between corona anxiety and death anxiety. This result can be considered as a reflection of the increased anxiety levels in HD patients.

Notably, in the study, it is remarkable that the risk of psychological distress, death anxiety and suicide probability increases common in patients with age of above 75 and need of self-care or social support. In accordance with this results, it was found that elderly patients experienced severe death anxiety during COVID-19 [42, 43]. Furthermore, it has been declared by the WHO and Turkish Statistical Institute that the suicide rate is highest above the age of $75[44,45]$. In another study, it was found that a functional family and social support reduced the risk of suicide in patients [46]. So, it was evaluated that these patients were more susceptible to mental health problems. Therefore, these patients should have priority in psychosocial support.

HD patients, who suffer from a chronical illness, experienced various psychological problems during the COVID-19 pandemic. The findings of this study indicated the considerable psychopathological problems experienced by HD patients such as depression, anxiety somatization, obsession, interpersonal sensitivity, hostility, phobic anxiety, paranoid ideation, psychoticism, psychological distress, corona anxiety and death anxiety. In the context of COVID-19, factors such as uncertainty about the course of the pandemic, lack of curative treatment, overload of information, limited social and physical activities may be causal or precipitating factors for these psychiatric symptoms in HD patients.

Notably, the risk of suicide and death anxiety are more important issues to be evaluated in HD patients, may negatively affect the course of treatment and even cause them to stop treatment [34,37]. The results of the study also indicated that death anxiety and the probability of suicide are the issues that should be assessed carefully in these patients. Factors such as the highly transmission of the SARS-CoV-2, the fatal course of COVID-19, being more susceptible to COVID-19, may caused or increased these symptoms in HD patients. 
This study has limitations. First, because of the cross-sectional design, the results indicated the psychological conditions within a certain period of pandemic. Thus there is a need for longer term studies to investigate changes over time. Second, this study was single-center and the generalizability of the results is limited as the study sample cannot be representative of all HD patients. Therefore, multicenter studies with larger samples are needed. Third, due to the design of the study, the temporal variation of psychosocial effects could not be evaluated. Studies in prospective or case-control design will more useful results. Lastly, when compared to other chronical diseases, there are much less comprehensive studies on the psychological conditions of HD patients during COVID-19. Because of no highly similar studies in the literature were found, comparison with the results of the study was not possible. Therefore, comparisons were made with the results of studies conducted before COVID-19. Despite these limitations, present study contains results that can be useful and guiding for future studies.

As a result, it was concluded that HD patients experienced serious psychopathological problems during the COVID-19 pandemic. The emerging mental health issues related to this global event may disrupt their course of treatment and develop into long-term health problems. Psychosocial support and interventions need to be planned by the healthcare system and healthcare providers to help HD patients in managing their disease and related mental health conditions as soon as. Psychoeducation should be given to patients and caregivers by mental health providers (e.g. psychologist, psychiatrist) on issues such as coping with negative psychological consequences, gaining problem-solving skills, and gaining mental health-promoting behaviors. In addition, the risk of suicide in HD patients should be identified early and appropriate treatment should be offered. Early detection of suicide risk may be possible with regular psychological screening and a high awareness of healthcare providers (e.g. nurse, doctor) about risk-related factors. Finally, due to the limited number of studies, more studies are needed to confirm the findings of this study in a larger sample and comprehensively to evaluate the psychopathological effect of the pandemic on HD patients.

\section{Declarations}

Acknowledgments: The author thanks to statistician Ass. Prof. Alper SiNAN who assisted in the statistical analysis of the study.

Informed Consent: Informed consent was obtained from the individuals who participated in this study.

Conflict of Interest: The author has no conflict of interest to declare.

Financial Disclosure: The author declared that he covered the financial expenses of the study. This work has not been supported by any grant.

\section{References}

1. World Health Organisation. Coronavirus. https://www.who.int/health-topics/coronavirus

2. Coronaviridae Study Group of the International Committee on Taxonomy of Viruses (2020) The species Severe acute respiratory syndrome-related coronavirus: classifying 2019-nCoV and naming it SARS-CoV2. Nat Microbiol 5:536-544. https://doi.org/10.1038/s41564-020-0695-z 
3. Seyahi N, Ateş K, Süleymanlar G (2017) Türkiye’de Renal Replasman Tedavilerinin Güncel Durumu: Türk Nefroloji Derneği Kayıt Sistemi 2015 Yılı Özet Raporu. Türk Nefroloji Diyal ve Transplant Derg 26:154160

4. Palmer S, Vecchio M, Craig JC, Tonelli M, Johnson DW, Nicolucci A, Pellegrini F, Saglimbene V, Logroscino G, Fishbane S, Strippoli GFM (2013) Prevalence of depression in chronic kidney disease: systematic review and meta-analysis of observational studies. Kidney Int 84:179-191. https://doi.org/10.1038/KI.2013.77

5. Henry BM, Lippi G (2020) Chronic kidney disease is associated with severe coronavirus disease 2019 (COVID-19) infection. Int Urol Nephrol 52:1193-1194. https://doi.org/10.1007/S11255-020-02451-9

6. Zhou F, Yu T, Du R, Fan G, Liu Y, Liu Z, Xiang J, Wang Y, Song B, Gu X, Guan L, Wei Y, Li H, Wu X, Xu J, Tu S, Zhang Y, Chen H, Cao B (2020) Clinical course and risk factors for mortality of adult inpatients with COVID-19 in Wuhan, China: a retrospective cohort study. Lancet (London, England) 395:1054-1062. https://doi.org/10.1016/S0140-6736(20)30566-3

7. Xiong F, Tang H, Liu L, Tu C, Tian JB, Lei CT, Liu J, Dong JW, Chen WL, Wang XH, Luo D, Shi M, Miao XP, Zhang C (2020) Clinical Characteristics of and Medical Interventions for COVID-19 in Hemodialysis Patients in Wuhan, China. J Am Soc Nephrol 31:1387-1397. https://doi.org/10.1681/ASN.2020030354

8. Wu J, Li J, Zhu G, Zhang Y, Bi Z, Yu Y, Huang B, Fu S, Tan Y, Sun J, Li X (2020) Clinical Features of Maintenance Hemodialysis Patients with 2019 Novel Coronavirus-Infected Pneumonia in Wuhan, China. Clin J Am Soc Nephrol 15:1139-1145. https://doi.org/10.2215/CJN.04160320

9. Hao W, Tang Q, Huang X, Ao L, Wang J, Xie D (2021) Analysis of the prevalence and influencing factors of depression and anxiety among maintenance dialysis patients during the COVID-19 pandemic. Int Urol Nephrol 53:1453-1461. https://doi.org/10.1007/S11255-021-02791-0

10. Liu CH, Yeh MK, Weng SC, Bai MY, Chang JC (2017) Suicide and chronic kidney disease: a case-control study. Nephrol Dial Transplant 32:1524-1529. https://doi.org/10.1093/NDT/GFW244

11. Kurella M, Kimmel PL, Young BS, Chertow GM (2005) Suicide in the United States End-Stage Renal Disease Program. J Am Soc Nephrol 16:774-781. https://doi.org/10.1681/ASN.2004070550

12. Derogatis (1975) Brief Symptom Inventory

13. Derogatis (1982) “Brief Symptom Inventory: Administration and procedures manual-I. Baltimore: Clinical Psychometric Research.” (1982)

14. Derogatis LR (1993) The Brief Symptom Inventory (BSI). Administration, Scoring and Procedures Manual II. Clinical Psychometric Research, Baltimore, MD

15. The validity, reliability and factor structure of the Brief Symptom Inventory

16. Thorson JA, Powell FC (1992) A revised death anxiety scale. Death Stud 16:507-521. https://doi.org/10.1080/07481189208252595

17. Sahin NH, Durak Batigun A, Ugurtas S (2002) The validity, reliability, and factor structure of the Brief Symptom Inventory (BSI). [in Turkish]. Turkish J Psychiatry 13(2):125-135. https://doi.org/10.1080/07481187.2016.1158752

18. Cull JG, Gill WS (1989) “Suicide probability scale (SPS)." Los Angeles. Western Psychological Services 
19. Atlı Z, Eskin M, Dereboy Ç (2009) The validity and the reliliability of Suicide Probability Scale (SPS) in clinical sample. J Clin Psychiatry 12(3):111-124

20. Lee SA (2020) Coronavirus Anxiety Scale: A brief mental health screener for COVID-19 related anxiety. Death Stud 44:393-401. https://doi.org/10.1080/07481187.2020.1748481

21. Lee SA (2020) Replication analysis of the Coronavirus Anxiety Scale. Dusunen Adam J Psychiatry Neurol Sci. https://doi.org/10.14744/DAJPNS.2020.00079

22. Biçer I, Çakmak C, Demir H (2020) Coronavirus Anxiety Scale Short Form: Turkish Validity and Reliability Study. Anadolu Klin Tıp Bilim Derg 25:216-225. https://doi.org/10.21673/anadoluklin.731092

23. WHO COVID-19 Dashboard. Accessed November 8 (2021) Available online: https://covid19.who.int/

24. Xiang YT, Yang Y, Li W, Zhang L, Zhang Q, Cheung T, Ng CH (2020) Timely mental health care for the 2019 novel coronavirus outbreak is urgently needed. The lancet Psychiatry 7:228-229.

https://doi.org/10.1016/S2215-0366(20)30046-8

25. Li S, Wang Y, Xue J, Zhao N, Zhu T (2020) The Impact of COVID-19 Epidemic Declaration on

Psychological Consequences: A Study on Active Weibo Users. Int J Environ Res Public Health 17:2032. https://doi.org/10.3390/ijerph17062032

26. Wang C, Pan R, Wan X, Tan Y, Xu L, Ho CS, Ho RC (2020) Immediate Psychological Responses and Associated Factors during the Initial Stage of the 2019 Coronavirus Disease (COVID-19) Epidemic among the General Population in China. Int J Environ Res Public Health 17:1729.

https://doi.org/10.3390/ijerph17051729

27. Stasiak CES, Bazan KS, Kuss RS, Schuinski AFM, Baroni G (2014) Prevalence of anxiety and depression and its comorbidities in patients with chronic kidney disease on hemodialysis and peritoneal dialysis. $J$ Bras Nefrol 36. https://doi.org/10.5935/0101-2800.20140047

28. Feroze U, Martin D, Kalantar-Zadeh K, Kim JC, Reina-Patton A, Kopple JD (2012) Anxiety and Depression in Maintenance Dialysis Patients: Preliminary Data of a Cross-sectional Study and Brief Literature Review. J Ren Nutr 22:207-210. https://doi.org/10.1053/j.jrn.2011.10.009

29. Özçetin A, Bahçebaşı B, Bahçebaşı T, Cinemre H, Ataoğlu A (2009) Diyaliz uygulanan hastalarda yaşam kalitesi ve psikiyatrik belirti dağılımı. Anadolu Psikiyatr Derg 10:142-150

30. Simões e Silva AC, Miranda AS, Rocha NP, Teixeira AL (2019) Neuropsychiatric Disorders in Chronic Kidney Disease. Front Pharmacol 10. https://doi.org/10.3389/fphar.2019.00932

31. Lee J, Steel J, Roumelioti M-E, Erickson S, Myaskovsky L, Yabes JG, Rollman BL, Weisbord S, Unruh M, Jhamb M (2020) Psychosocial Impact of COVID-19 Pandemic on Patients with End-Stage Kidney Disease on Hemodialysis. Kidney360 1:1390-1397. https://doi.org/10.34067/KID.0004662020

32. Sezer MT, Eren I, Ozcankaya R, Civi I, Erturk J, Ozturk M (2003) Psychological Symptoms Are Greater in Caregivers of Patients on Hemodialysis Than Those of Peritoneal Dialysis. Hemodial Int 7:332-337. https://doi.org/10.1046/j.1492-7535.2003.00058.x

33. Fathi sanagoo (2016) Death Anxiety in Hemodialysis Patients Admitted to Panj-Azar Teaching Hospital. Death Anxiety in Hemodialysis Patients Admitted to Panj-Azar Teaching Hospital. 12:48-55

34. Martin CR, Thompson DR (2000) Prediction of quality of life in patients with end-stage renal disease. $\mathrm{Br}$ J Health Psychol 5:41-55. https://doi.org/10.1348/135910700168757 
35. Arrowood RB, Cox CR, Kersten M, Routledge C, Shelton JT, Hood RW (2017) Ebola salience, death-thought accessibility, and worldview defense: A terror management theory perspective. Death Stud 41:585-591. https://doi.org/10.1080/07481187.2017.1322644

36. Javed S, Bangash SS, Sharf N, Samman B, Alvi T (2021) Death Anxiety in Hemodialysis Patients before and during the Outbreak of COVID-19: A Longitudinal Study. Life Sci 2:4.

https://doi.org/10.37185/LnS.1.1.140

37. Cohen LM, Dobscha SK, Hails KC, Pekow PS, Chochinov HM (2002) Depression and suicidal ideation in patients who discontinue the life-support treatment of dialysis. Psychosom Med 64:889-896. https://doi.org/10.1097/01.PSY.0000028828.64279.84

38. Cohen LM, Germain MJ (2008) Psychosocıal Factors In Patıents With Chronıc Kıdney Disease: The Psychiatric Landscape of Withdrawal. Semin Dial 18:147-153. https://doi.org/10.1111/j.1525139X.2005.18201.x

39. Ueda M, Nordström R, Matsubayashi T (2021) Suicide and mental health during the COVID-19 pandemic in Japan. J Public Health (Bangkok). https://doi.org/10.1093/pubmed/fdab113

40. Labrague LJ, Santos JAA (2020) COVID-19 anxiety among front-line nurses: Predictive role of organisational support, personal resilience and social support. J Nurs Manag 28:1653-1661. https://doi.org/10.1111/jonm.13121

41. Lee SA, Jobe MC, Mathis AA, Gibbons JA (2020) Incremental validity of coronaphobia: Coronavirus anxiety explains depression, generalized anxiety, and death anxiety. J Anxiety Disord 74. https://doi.org/10.1016/J.JANXDIS.2020.102268

42. Zhang J, Peng J, Gao P, Huang H, Cao Y, Zheng L, Miao D (2019) Relationship between meaning in life and death anxiety in the elderly: self-esteem as a mediator. BMC Geriatr 19:308. https://doi.org/10.1186/s12877-019-1316-7

43. Yao H, Chen J-H, Xu Y-F (2020) Patients with mental health disorders in the COVID-19 epidemic. The Lancet Psychiatry 7:e21. https://doi.org/10.1016/S2215-0366(20)30090-0

44. World Health Organization. Preventing suicide: A global imperative. World Health Organization, 2014

45. Turkish Statistical Institute (2014) Suicide statistics. (Turkey)

46. Compton MT, Thompson NJ, Kaslow NJ (2005) Social environment factors associated with suicide attempt among low-income African Americans: The protective role of family relationships and social support. Soc Psychiatry Psychiatr Epidemiol 40:175-185. https://doi.org/10.1007/s00127-005-0865-6

\section{Tables}

Table 1. Sociodemographic characteristics of participants $(n=114)$ 


\begin{tabular}{|c|c|c|}
\hline & & $\mathrm{n}$ \\
\hline \multirow[t]{3}{*}{ Age } & $50>$ & 1614 \\
\hline & $50-75$ & 7666.7 \\
\hline & $75<$ & 2219.3 \\
\hline \multirow[t]{2}{*}{ Gender } & male & 6052.6 \\
\hline & femal & 5447.4 \\
\hline \multirow[t]{2}{*}{ Marital status } & marri & 98271.9 \\
\hline & single & 3228.1 \\
\hline \multicolumn{2}{|c|}{ Graduated from a universityyes } & 4035.1 \\
\hline & no & 7464.9 \\
\hline \multirow[t]{2}{*}{ Living with family } & yes & 9381.5 \\
\hline & no & 2118.5 \\
\hline \multirow[t]{2}{*}{ History of pyschiatric disea } & syees & 3328.9 \\
\hline & no & 8171.1 \\
\hline \multirow{2}{*}{$\begin{array}{l}\text { Need of self-care or social } \\
\text { support }\end{array}$} & yes & 3228.1 \\
\hline & no & 8271.9 \\
\hline \multirow[t]{2}{*}{ History of suicidal ideation } & yes & 2017.6 \\
\hline & no & 9482.4 \\
\hline
\end{tabular}

Table 2. Comparisons of the mean total scores of TDAS, SPS, CAS (score of $\geq 5$ ) and GSI between th sociodemographic characteristics 


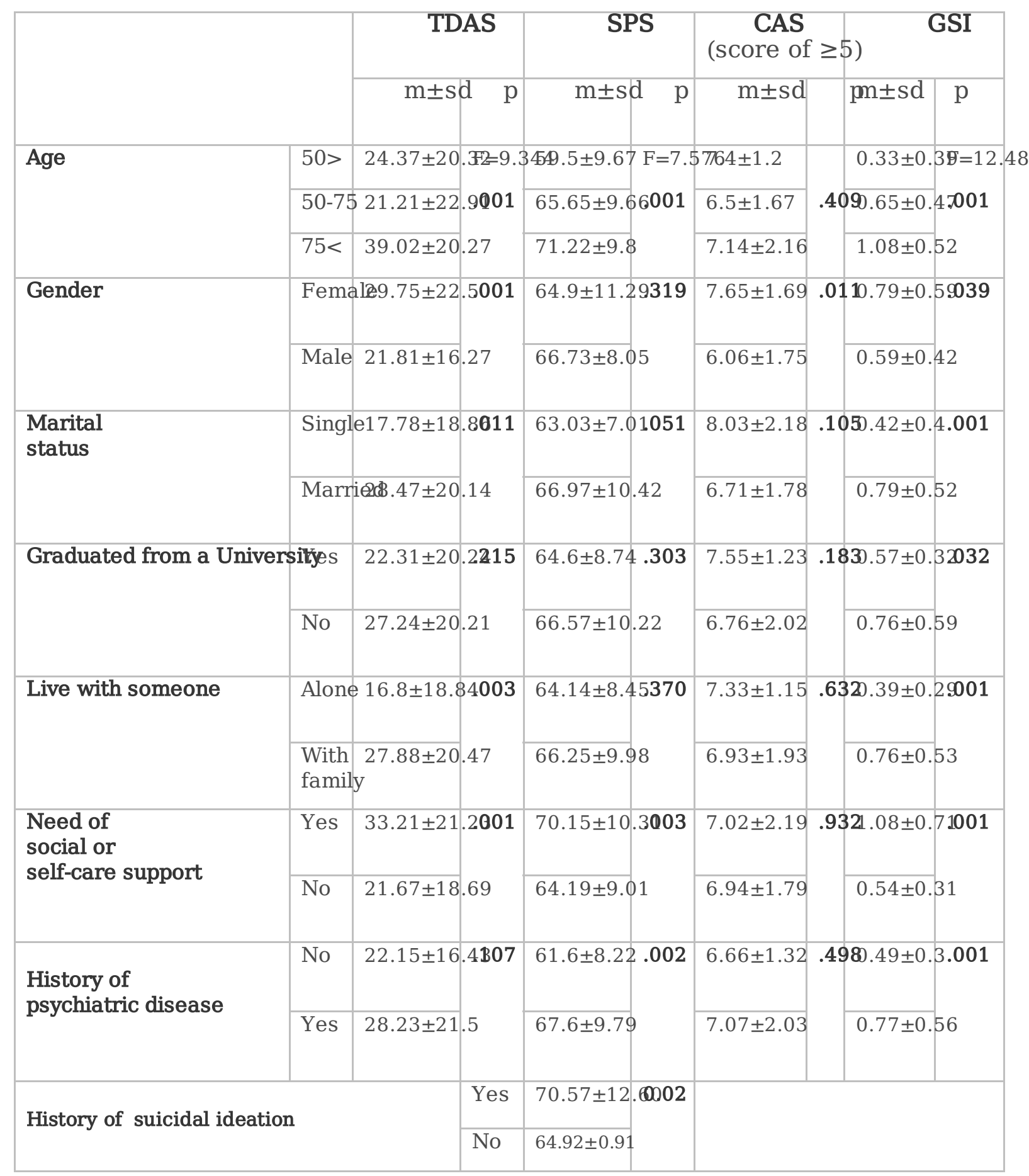

F: ANOVA test, TDAS: Turkish death anxiety scale, SPS: Suicide probability scale, CAS: Coronavirus anxiety scale, BSI: Brief symptom inventory, GSI: Global severity index

Table 3. Correlation of suicide probability, death anxiety, corona anxiety and psychological distress 


\begin{tabular}{|c|c|c|c|}
\hline & \multicolumn{3}{|c|}{$\begin{array}{c}\text { Death anxiefyorona anxie Bsychologic } \\
\text { distress }\end{array}$} \\
\hline Suicide probability & $\begin{array}{l}\mathrm{r}=0.113 \\
\mathrm{p}=0.231\end{array}$ & $\begin{array}{l}\mathrm{r}=0.042 \\
\mathrm{p}=0.66\end{array}$ & $\begin{array}{l}r=0.442 \\
p=0.001\end{array}$ \\
\hline Death anxiety & & $\begin{array}{l}r=0.651 \\
p=0.001\end{array}$ & $\begin{array}{l}r=0.667 \\
p=0.001\end{array}$ \\
\hline Corona anxiety & & & $\begin{array}{l}r=0.414 \\
p=0.001\end{array}$ \\
\hline
\end{tabular}

r: Pearson correlation analyse 